\title{
Detection of Vector Mosquito of Filariasis in the Endemic Areas of Bangladesh
}

\author{
Jasmin Nur, Bilkis Sultana, Mohammad Hefzur Rahman, and Mohammad Moniruzzaman
}

\section{ABSTRACT}

\begin{abstract}
Background: Lymphatic Filariasis (LF), a mosquito born tropical parasitic disease, caused by Wuchereria bancrofti is not only a health but also a socio-economic problem in Bangladesh. Culex quinquefasciatus is the confirmed filarial vector in Bangladesh, so by controlling of this vector population, we can prevent this disease. To control this vector and decrease incidence of filariasis, we need to know studied mosquito's sample in endemic areas.
\end{abstract}

\begin{abstract}
Aim and objectives: Aim of this study was to see mosquito population in search of vector species in the endemic zones of malaria and filarial. Then we confirmed presence of vector species at molecular level by species specific DNA fingerprinting.
\end{abstract}

Methods: This cross-sectional entomological study was carried out in Hobiganj (Shatchori tea garden) and Moulvibazar district (Patrokhola and Madonmohonpur tea gardens). Mosquito was collected by paper cup with net, aspirator and torch light and vector mosquitoes were identified with stereoscopic microscope. After identification of the mosquitoes, these were stored in laboratory for analysis of the density of the vector mosquitoes in the endemic areas. Then the vector mosquitoes were identified through molecular method named Polymerase Chain Reaction (PCR).

Result: 1427 female mosquitoes belonging to 28 species under 5 genera were collected from three tea gardens. Culex quinquefasciatus which is the confirmed filarial vector in Bangladesh was found high in number (20.74\%) out of the total collected mosquitoes. Other mosquito's species were found in various ratios. Then Culex quinquefasciatus vector was identified by PCR.

Conclusion: As vector mosquitoes of $\mathrm{LF}$ are available in these tea gardens, the study concludes that these areas are highly LF endemic areas of Bangladesh. Through molecular method, the vector of $L F$ can be identified certainly. As we identify the vector mosquito, thus we can prevent this $L F$ disease at very early stage. So, these findings will be very beneficial and cost effective for a developing country like Bangladesh.

Keywords: Culex quinquefasciatus, Lymphetic Filariasis, Polymerase Chain Reaction.

\section{INTRODUCTION}

A vector-borne disease is that in which the pathogenic microorganism is transmitted from an infected individual to another one by an arthropod or other agents, sometimes with other animals serving as intimidator host. Although invertebrate such as mosquitoes and tics play the main role for diseases transmission, but some vertebrates may also act as vectors. Filariasis is a mosquito born tropical disease which is very harmful and causes endemic disease. Although various thread-like nematode (worm) parasites and their larvae belonging to the family Filarioidea are responsible for
Submitted : May 17, 2021

Published : June 25, 2021

ISSN: $2593-8339$

DOI: 10.24018 /ejmed.2021.3.3.881

Jasmin Nur*

Research officer, Immunology

Department, BIRDEM, Bangladesh.

(e-mail: nubanubala@gmail.com)

Bilkis Sultana

Scientific Assistant, Immunology

Department, BIRDEM, Bangladesh.

(e-mail: bilkis78.bs@gmail.com)

Mohammad Hefzur Rahman

Emergency Response Manager, COVID19 Pandemic Project, Shimantic, Dhaka, Bangladesh.

(e-mail: mhefzur@yahoo.com)

Mohammad Moniruzzaman

Assistant Professor, Department of Immunology, Bangladesh University of Health Science, Dhaka, Bangladesh.

(e-mail: moniruzzaman@buhs.ac.bd)

*Corresponding Author this disease, W. bancrofti is the main causative agent of Filariasis. Different mosquito's species like Culex, Anopheles and Mansonia species are the vectors of this Filariasis. Among these Culex quinquefasciatus is the main vector of this disease. Approximately 120 million people in the tropical and subtropical areas of Southeast Asia, South America, Africa, and the islands of the Pacific are affected by various debilitating parasitic diseases [1]. Among them Lymphatic Filariasis (LF) is predominant. About $90 \%$ of LF infection occurred worldwide due to $\mathrm{W}$. bancrofti and rest $10 \%$ for B. malayi [2]. LF is occurred when the adult worms distort the lymphatic vessels and cause local inflammation 
and swelling. In case of LF, symptoms have shown many years later. Around 10 to 15 years repeated exposure to the parasite of a person LF is established. In case of these diseases 10 to 50 percent of men suffer from genital damage, especially hydrocele (fluid- filled balloon-like enlargement of the sacs around the testes) and elephantiasis of penis and scrotum. These manifestations are mostly irreversible and cause of socio-physical problem to patients and often their families. Chronic lymphatic filariasis causes severe functional impairment and disability [3]-[5] and loss of productivity [6].

Bangladesh is a highly endemic area for LF. As Bangladesh is an overcrowded area and most of the people in this country are poor and live in unhygienic condition, LF is a major public health problem in Bangladesh. It makes them incapable to earn and help their own family. Genital damage especially hydrocele and elephantiasis of scrotum in men and of the breasts in women occur much more frequently. W. bancrofti is the only causative agent of LF in both rural and urban areas in Bangladesh and Culex quinquefasciatus is the only vector of this parasite [7], [8]. About 70 million people in 32 of the 64 districts in the country are at risk of infection. WHO estimated that about $50 \%$ of the districts have been found to be endemic [9]. About one million people caring microfilaria ( $\mathrm{mf}$ ) and half a million cases with clinical manifestations are found LF affected areas in Bangladesh [10]. This disease is found almost all the districts in Bangladesh but highly prevalence in Northwestern areas including Thakurgone, Rangpur, Dinajpur, Rajshahi and Nilphamari [11]. It is also endemic in Eastern hilly and forest parts of Bangladesh [12]. The topographical area of both Hobiganj and Moulvibazar districts are same. In case of Satchari tea garden, most of the areas were hilly and the rest area is rather flat and foothill. Sluggish water was found by the side of the flowing streams serve as breeding (reproduction place) source for mosquitoes. Most of the areas of Modonmohonpur tea garden and Patrokhola tea garden are flat. Small portion of these two gardens are hilly and forested. In all these tea gardens there were many drains of fresh water passing through the gardens which was used for tea plants. Such drains also serve as breeding sources of mosquitoes. This area is known for heavy rainfall and numerous "Shed trees" in the tea gardens. Such shaded area is also conducive to some mosquitoes to survive and develop. As LF is transmitted through mosquitoes, so by detection of vector mosquitoes we can control vector mosquitoes in the endemic zone to prevent diseases progression.

\section{METHOD AND MATERIALS}

This cross-sectional entomological study was carried out in Satchari tea garden of Chunurughat upazilla in Hobiganj district and Patrokhola and Madonmohonpur tea gardens in Kamalganj union of Moulvibazar district. Total duration of this study was six months. Mosquitoes were collected from both Hobiganj \& Moulvibazar tea garden. Aspirator and torchlight were used for collecting the mosquitoes (Fig. 1).

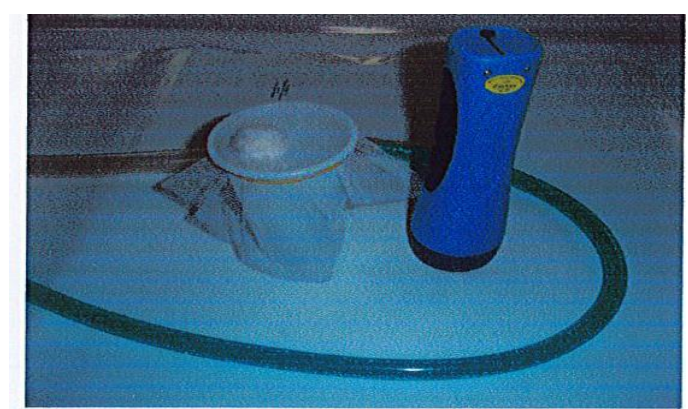

Fig. 1. Mosquito collection instruments: paper cup with net, aspirator, and torch light.

Mosquitoes were collected mostly from human living houses. Some were collected from cattle houses. After collection and brought to the laboratory of the department of Biochemistry and Molecular Biology of Dhaka University, The mosquitoes were then identified with Stereoscopic microscope with the help of some mosquito practice book. ${ }^{13-}$ 16 After identification the mosquitoes were stored in the laboratory for analysis of the density of the vector mosquitoes in the endemic areas and for identifying the vector mosquitoes through molecular method, Polymerase Chain Reaction (PCR).

In case of PCR method, at first deoxyribonucleic acid (DNA) should be extracted from mosquitoes' genome. For extraction of whole DNA from mosquito genome, the materials and method are used according to protocol followed by Linton and his colleagues [17]. This DNA was used as template DNA for PCR. For the identification of species of Culex quinquifesciatus the list of reagents and its amount was used and the PCR protocol was followed according to the species-diagnostic polymerase chain reaction assay done by Crabtre [18]. According to this procedure at first primers were prepared which were collected from Commonwealth Scientific Industrial Research Organization (CSIRO), Australia. Sequences of the forward and reverse primers are given below:

\section{Forward- PQIO (19-mer): \\ 5'CCTATGTCCGCGTATACTA 3'}

Reverse- CPI6 (29mer): 5'GCGGGTACCATGCTTAAATTTAGGGGGTA 3'

After primer preparation the same way stock solution, working solution of the dNTPs mixture, PCR master mixture, reaction mixture, PCR master mixture for Tag polymerase were prepared. As the PCR were performed in Thermal Cycler. By gradient the annealing temperature of primer was optimized which is 8 . The gradient program was designed by keeping $55.1^{\circ} \mathrm{C}$ in middle. After amplification the PCR products were identified by agarose gel electrophoresis (1.8\% agarose). For the determination of the length of the PCR product the marker was used which is $1 \mathrm{~kb}+$ (Invitrogen). After agarose gel electrophoresis, bands for the DNA fragments were visualized by UV trans-illuminator and photographed by gel documentation analysis system. 


\section{Result}

\section{A. Mosquito Population Study}

In this study a survey has been conducted in Hobiganj and Moulvibazar areas and various types of mosquitoes were collected through the work. The findings are presented in the follow:

TABLE I: MOSQUito's SPECIES AND THEIR PROPORTION IN THREE TEA GARDENS OF HOBIGANJ AND MOULVIBAZAR

\begin{tabular}{|c|c|c|c|c|}
\hline $\begin{array}{l}\text { Si. } \\
\text { No }\end{array}$ & Name of species & $\begin{array}{l}\text { Total } \\
\text { Nos. }\end{array}$ & $\%$ & $\begin{array}{l}\text { Per-man } \\
\text { Hour catch(56 hours) }\end{array}$ \\
\hline 1 & Aedes) lineatopennis & 2 & 0.14 & 0.04 \\
\hline 2 & Anopheles barbirostris & 3 & 0.21 & 0.05 \\
\hline 3 & An. nigerrimus & 153 & 10.72 & 2.73 \\
\hline 4 & An.umbrosus & 2 & 0.14 & 0.04 \\
\hline 5 & An. annularis & 1 & 0.07 & 0.07 \\
\hline 6 & An. karwari & 1 & 0.07 & 0.07 \\
\hline 6 & An. kochi & 1 & 0.07 & 0.07 \\
\hline 8 & An. philippinensis & 45 & 3.15 & 0.80 \\
\hline 9 & An.pseudojamesi $\quad(=$ ramsayi $)$ & 1 & 0.07 & 0.07 \\
\hline 10 & An subpictus & 15 & 1.05 & 0.27 \\
\hline 11 & An.vagus & 42 & 2.94 & 0.75 \\
\hline 12 & Armigeres kuchingensis & 55 & 3.85 & 0.98 \\
\hline 13 & Culex annulus & 6 & 0.42 & 0.11 \\
\hline 14 & Cx.bitaeniorhynchus & 1 & 0.07 & 0.07 \\
\hline 15 & Cx epidesmus & 5 & 0.35 & 0.09 \\
\hline 16 & Cx. fuscocephala & 92 & 6.45 & 1.64 \\
\hline 17 & $C x$, gelichus & 139 & 9.74 & 2.48 \\
\hline 18 & Cx hutchinsoni & 3 & 0.21 & 0.05 \\
\hline 19 & Cx. mimulus & 1 & 0.07 & 0.07 \\
\hline 20 & Cx.quinquefasciatus & 296 & 20.74 & 5.29 \\
\hline 21 & Cx.sinensis & 1 & 0.07 & 0.07 \\
\hline 22 & $C x$. tritaeniorhynchus & $149 \mathrm{~h}$ & 10.44 & 2.66 \\
\hline 23 & Cx.vishnui & 345 & 24.18 & 6.16 \\
\hline 24 & Cx.whitmorei & 11 & 0.77 & 0.19 \\
\hline 25 & Cx. fragilis & 2 & 0.14 & 0.04 \\
\hline 26 & Mansonia annulifera & 17 & 1.19 & 0.3 \\
\hline 27 & Ma. Indiana & 6 & 0.42 & 0.11 \\
\hline 28 & Ma. uniformis & 32 & 2.24 & 0.57 \\
\hline \multicolumn{2}{|r|}{ Total } & 1427 & & 25.19 \\
\hline
\end{tabular}

All together 1427 adult female mosquito belonging to 28 species under five genera were collected from Shatchori tea garden in Hobiganj and Patrokhola and Modonmohonpur tea garden in Moulvibazar. In the overall collected mosquitoes in three tea gardens Culex vishuui was found in highest amount $(24.18 \%)$ followed by Culex quinquefasciatus (20.74\%), An.nigerrimus (10.72\%), Cx.geledus (9.74\%) and Cx.fuscocephala $(9.74 \%)$. Besides these other species were collected in small number. Proportion of several of mosquitoes genera in three tea gardens are given below:

From Fig. 2, it is shown that in all tea garden in the study area the number of Culex genus mosquitoes was high. Individual in Patrokola and Modonmohonpur Tea garden, the number of Culex genus was high then Anopheles and then other genera. But in Shatchori tea garden number of this culex genus was low. Here number of Anopheles genus mosquito was high, followed by culex armigerus and then others.

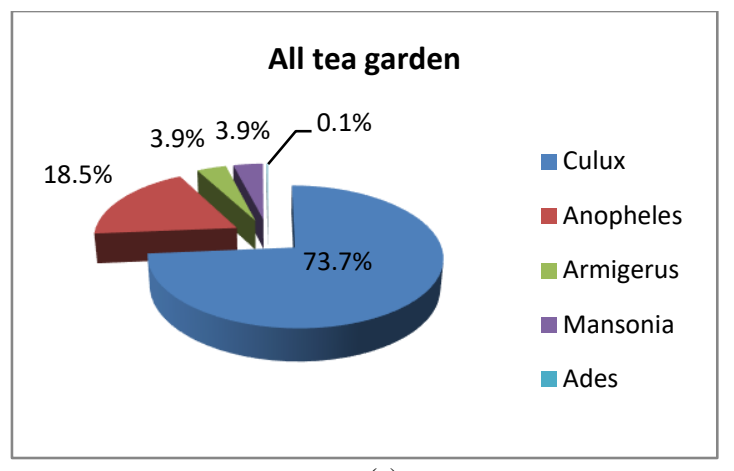

(a)

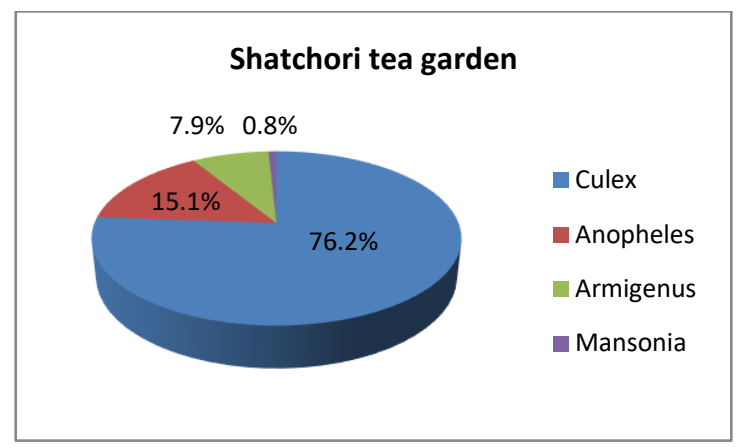

(b)

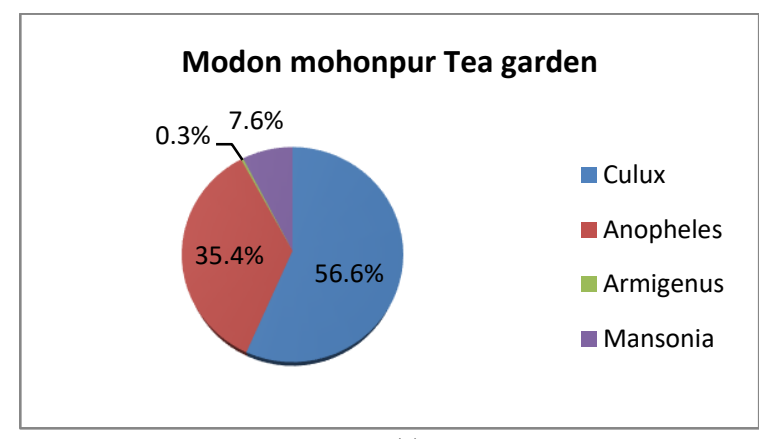

(c)

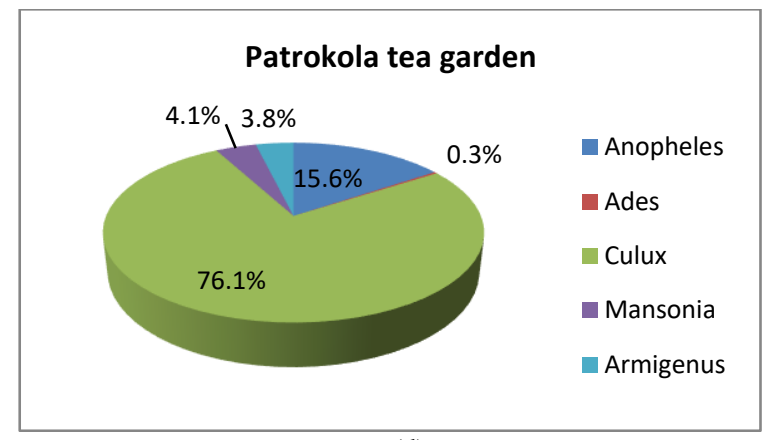

(d)

Fig. 2. Proportion of several mosquitoes genera in different tea garden.

(a) Percentage of five genera in all tea garden; (b) Percentage of four mosquito genera in Shatchori tea garden; (c)Percentage of four mosquito genera in Modonmohonpur Tea garden; (d) Percentage of five mosquito genera in Patrokola tea garden.

\section{B. Detection of Vector Mosquito by Using Polymerase Chain Reaction (PCR):}

Whole DNA was extracted from Filarial vector mosquito Culex quinquefasciatus and amplified by PCR method using species specific primers,

Forward- PQIO (19-mer): 5'CCTATGTCCGCGTATACTA 3' Reverse- CPI6 (29mer): 


\section{5'GCGGGTACCATGCTTAAATTTAGGGGGTA 3'}

which was amplified the $28 \mathrm{~S}$ ribosomal gene of these mosquitoes. These primers are specific for this $28 \mathrm{~S}$ ribosomal gene of this $\mathrm{Cx}$. quinquefasciatus species. After amplification the amplified product was identified by agarose gel electrophoresis. After run through the gel, the gel was then stained with Ethidium Bromide. Then the band size which is 698 of the amplified products was observed under UV light. The result has been shown in Fig. 3.

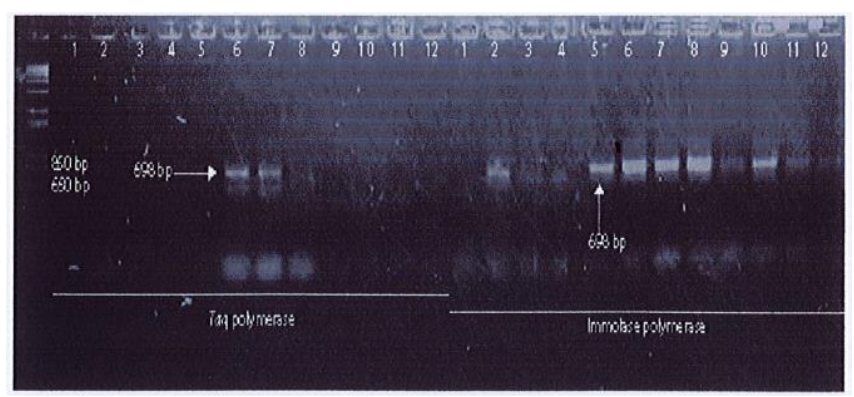

Fig. 3. Agarose gel electrophoresis of the PCR product of Cx. quinquefasciatus mosquito DNA.

Through this amplification program it can be ascertained that mosquito is truly the $\mathrm{Cx}$. quinquefasciatus which is the only filarial vector in Bangladesh. These mosquitoes were collected from three tea gardens in both Hobiganj and Moulvibazaar.

\section{DISCUSSION}

Bangladesh like other tropical countries is a breed house of different types of mosquitoes. Diseases like Filariasis, Malaria, Japanese encephalitis and Dengue are rampant in our country. Due to poor socioeconomic condition large section of our population has to co-inhabit with mosquitoes. As a result, the above mentioned mosquitoes born diseases are endemic in this country. Eradication of mosquitoes under present socioeconomic graphical status is not possible. However, development of quick diagnostic process to detect and control it may be possible in near future. In this context it is essential to understand the various species of mosquitoes and specially those which are vectors for above diseases, such as Filariasis. With this idea in mind a survey of mosquito population and their characterization was undertaken. Habiganj and Moulovibazar area was selected in the first place to have a preliminary idea about vector mosquito population of filariasis and to identify them in molecular method (PCR).

Overall, 1427 mosquitoes under 28 species were collected from three tea gardens in Habiganj and Moulovibazar. Among the collected mosquitoes three out of thirteen were Anopheles mosquitoes which were malaria vectors (An. philippinensis, An. Annularis and An. Vagus). Among these malaria vectors An. philippinensis is the primary vector found in high amount $(3.15 \%)$ and rest of two are secondary malarial vector. Among these 13 types of collected mosquitoes the Cx. Quinquefasciatus which is recognized as confirmed Bancroftian filariasis vector in Bangladesh 15 was found in significant amount (20.18\%). It was found in highest number in both Patrokhola (24.0\%) and Modonmohonpur
(24.04\%) tea gardens but insignificant $(2.8 \%)$ in Shatchori tea garden in Hobiganj. Because this Cx Quinquefasciatus species reproduce in steady and polluted water and maximum places of labours houses in patrokhola and Modonmohonpur tea gardens were flat. Many holes were available, and some drains were passed beside the houses of the labours where steady and polluted water was stored. This polluted and steady water is suitable for breeding of these mosquitoes. For this reason, this mosquito was found in these two gardens. As maximum areas of Shatchori tea garden is hilly so this mosquito cannot breed here. Prevalence of a disease in a certain area depends on the presence of respective vector mosquitoes in that area. So, presence of large number of this species in this area it assumed that transmission of LF is continuing over this area.

Taxonomically vector mosquito can identify but it is not reliable because the closely related grouping mosquitoes cannot be identified with certainly. Molecular method i.e. PCR is very sensitive method to identify the any type of animal or parasitic genome. For this purpose, vector mosquitoes of various diseases can be identified precisely by this method.

Using the species' specific primer of the Culex quinquefasciatus the confirm vector of Bancroftian filariasis in Bangladesh was identified through this method. ${ }^{7}$ By this method the vector of other diseases can be perfectly identified using their species' specific primer. As the endemicity of a disease in a certain area is related to the prevalence of its vector in that area, so identifying a specific vector we can ascertain which disease is transmitted over that area. This process of identification of vector mosquito may help eradication of the diseases at early stage of that vector related disease. It is very cost effective and very helpful technique for developing country like Bangladesh to eradicate vector born diseases.

\section{CONCLUSION}

In this study we observed that Filariasis is endemic in certain areas of Bangladesh. These disabling diseases are affecting down the potentialities of low incoming group of people. Molecular marker may be very effective for rapid identification of the disease. And this may be a very helpful technique to eradicate the vector born disease like Filariasis in the very beginning of diseases progression.

\section{REFERENCES}

[1] Ottesen EA, Duke BO, Karam M, Behbehani K. Stetrigy and tools for the Control elimination of lymphatic filariasis. 75(6):491-503.1997.

[2] Behbehani K. Candidate parasite diseases. Bulletin of World Health Organization. 76 (Suppl 2), 64 - 67.1998.

[3] Gyapong JO, Gyapong M, Evans BD, Aikins MK and Adjei S. The economic burden of lymphatic filariasis in northern Ghana. Annuals of Tropical medicine and parasitological. 90:39-48.1997.

[4] Drayer G, Noros J, Addiss D. The silent burden of sexual disability associated with lymphatic filariasis. Acta tropica Jan;63(1):5760.1997.

[5] Ramaiah KD., Vijoy Kumar K, Ramu K, Pani SP and Das PK. Functional impairment caused by lymphatic filariasis in rural areas of south India. Tropical medicine and International health. 2:832838.1997.

[6] Ramu K, Ramaiah KD, Gyyatt H. and Evans DB. Impact of lymphatic filariasis on the productivity of male weavers in south Indian village. 
Transactions of the loyal society of Tropical medicine and hygine. 90(6):669-70.1996.

[7] Ahmed TU, Masheswary NP and Khan NI. Filariasis in Mirpur area of Dhaka city. Bangladesh Medical Research Council. Dec;12(2):8394.1986.

[8] Annual report. Communicable diseases control, Bangladesh.2012.

[9] WHO. Annual report of communicable disease Lymphatic filariasis. Current situation of South -East countries.2004.

[10] WHO. Annual report of communicable disease Lymphatic filariasis. 2000.

[11] WHO Bangladesh. Communicable disease, Epidemics under control for better surveillance and management .2004.

[12] Khanum H, Hossain I, Sarkar F and Zaman RF. Lymphatic filariasis in Nilphamari district: An endemic area in Bangladesh. Bangladesh J. Zool. 46(1): 11-19.2018.

[13] Barraud PJ. The fauna of British India, including Ceylon and Burma. (Diptera: Culicidae) Tribes Megarhinini and Culicini. Taylor and Francis, London. 2(1): 1-307.1934.

[14] Puri I.M. (1960). Synoptic table for the identification of the Anopheles mosquitoes of India.5th ed. Health Bull. No.10. Malaria Bureau, Govt. India press, Delhi. 1960.

[15] Bram RA. Contributions to the mosquito fauna of Southeast Asia-II. The genus Culex in Thailand (Diptera: Culicidae). Contribution of the American Entomological Institute; 2(I): 1-296.1967.

[16] Harrison BA and Scanlon JE. Medical entomology study genus Anopheles in Thailand (Dipter: Culicidae). Contributions of the American Entomological Institute; 2(1): 1-307.1975.

[17] Linton YM, Harbach R, Mohseng C, Anthony T, matusop A. Morphological and moleculer identity of anopheles (Cellia), Sundaicus (Dpitera: Culicidae), The nominotypical number of a vector species Complex in South East Asia. Systematic Entomology. 26: 357366.2001.

[18] Crabtree MA, Savage HM, and Miller BR. Development of a species diagnostic polymerase chain reaction assay for the identification of Culex vectors of ST. Louis encephalitis virus based on interspecies sequence variations in ribosomal DNA spacer. The American Journal of Tropical medicine and hygiene. 53 (1): 105-109.1995.

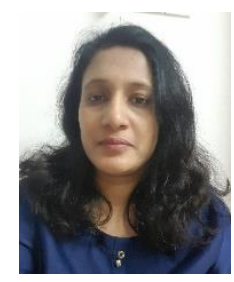

Jasmin Nur was born in 1983 in Shariatpur. She completed her secondary and higher school certificate from Dhaka in 1998 and 2000 respectively. She is an alumnus of Ideal school and College, Motijhil, Dhaka. She completed her M. S in Biochemistry and Molecular Biology and B. Sc in same subject from University of Dhaka. At present Jasmin Nur involves in research as a Research Officer at Immunology Department of Bangladesh Institute of Research and Rehabilitation in Diabetes, Endocrine and Metabolic Disorders (BIRDEM) at Shahbag, Dhaka, Bangladesh which is a 600-bed multidisciplinary hospital complex of the Diabetic Association of Bangladesh and a nationwide renowned medical and research organization. Prior to join here, she did her thesis and research activities on molecular detection of vector mosquito of Filariasis in University of Dhaka. She taught in Holy Cross School and College for a short period of time. Jasmin Nur is also a visiting faculty member under National University, Gazipur where she contributes herself in teaching her students, and supervising their dissertation. Her arena of interest is identification of human diseases and correlate with symptoms.

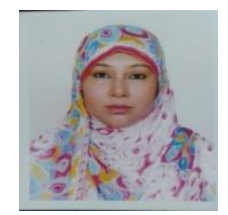

Bilkis Sultana originally from Faridpur completed secondary education from MDC Model School, Dhaka with 1st division and higher secondary education from Adamjee Cantonment college, Dhaka with 2nd division and Bachelor of Science from National University with 2nd class and Masters of Science from National University with 2nd class and Masters of Philosophy degree from Dhaka University with award and Bachelor of Laws Degree (LLB) from National university with 2nd class. After completing her MSc degree, she started her career with BIRDEM General Hospital as Scientific assistant January 2007 to till (14 years) now. She also worked in biochemistry, hematology, and immunology department of BIRDEM. She achieved a lot of experience about various type lab work and research. Besides she had one original paper, one original article, five abstracts. She is adaptive, hardworking and possesses good leadership qualities and aim to be a good researcher in the relevant field to my academic background.

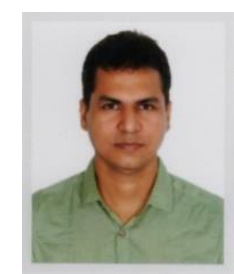

Mohammad Hefzur Rahman was born in October, 1976 in Dhaka. After that, he had completed his secondary (SSC) and higher school certificate (HSC) from Dhaka in 1991 and 1993 respectively. He had completed medical graduate from Sir Salimullah Medical College (SSMC) under University of Dhakain the year of 2000 and completed master's in public health (MPH) major in Epidemiology from ASA University, Bangladesh in the year of 2014. He has been working in the field of public health over fifteen years and has finished different type of project as a Project Manager at icddr'b, CHRF, Johns Hopkins University-Bangladesh, ASA, CIPRB and Shimantik NGOs.

At the beginning of his carrier, he had completed one-year Pediatrics training from BSMMU from July 2002 to June 2003. Also, had a fellowship training from icddr'b (from September 2005 to September 2006) and worked as a Medical officer at icddr'b in the research project of "Burden Of Pneumococcal Disease in Children in Bangladesh: A Project to Enhance Laboratory Capacity and Create Awareness, and to Prepare for Introduction of a Pneumococcal Vaccine in icddr,b" short name as PneuomoAdip from December 2006 to December 2008. During this Journey as a public health researcher, some of the important publication was published in the renowned journal's LANCET as a co-author. In very recently, he is involved with Covid-19 project named as USAID's Ma Moni Maternal and Newborn Care Strengthening Project: Emergency Response to COVID-19 Pandemic at different districts with the collaboration of save the children and DGHS which is funded by USAID.

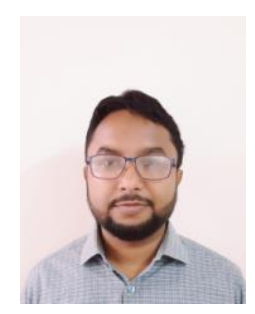

Mohammad Moniruzzaman born in 1983 in Dhaka, Bangladesh completed his Secondary school certificate (SSC) and Higher secondary certificate (HSC) exam from Haider Ali High School and Government Science College respectively. He graduated (MBBS) from Chittagong Medical College, Chittagong under the University of Chittagong in 2006. After completing his internship training, he served different Private Hospitals of Dhaka City for few years and then joined Dhaka City Corporation as Program Coordinator in Urban Primary Health Care Service Delivery Project (UPHCSDP). There he conducted various Public Health related field programs such as Immunization Program (EPI), Reproductive and Child Health care, Tuberculosis and HIV Control, Non-communicable Diseases Control and Health Education. After that he also worked as Medical Officer at National Health Care Network (NHN) (an enterprise of the Bangladesh Diabetic Association). He obtained the Master of Philosophy (M.Phil) degree in Immunology from BIRDEM Academy, under Bangabandhu Sheikh Mujib Medical University (BSMMU). During this period, he served as Honorary Lecturer (part time) in the Department of Immunology, Bangladesh University of Health Science (BUHS) for few months. Later, he joined the Department of Immunology, BUHS as Senior Lecturer in January 2016.

In July 2017 he promoted as Assistant Professor in the same department. During his tenure, he attended a number of National and International Conferences and involved in various projects of BIRDEM Academy funded by various organization such as Ministry of Science and Technology (MOST) and Bangladesh Medical Research Council (BMRC). He has been awarded with Fellowship from Bangladesh College of General Practitioner (BCGP) and also a life member of BCGP. He is Life-member of Bangladesh Medical Immunology Society (BMIS) and serves as Publication Secretary of BMIS. He also selected as Vice President in Bangladesh Human Right Commission (Mugda Thana, Dhaka) and took part in many health and social activities. He has published several article and case report in reputed national and international journals. He also presented his research works in various conferences and seminars. In BUHS he coordinates and supervised many students' dissertation, thesis, and research works. 